\title{
Lymphocyte Actinomycin Binding Capacity in Chronic Lymphocytic Leukaemia
}

Methods for the identification of cell surface immunoglobulin have been used to distinguish marrow-derived (B) and thymus-derived (T) lymphocytes in the normal circulating blood; they are involved in humoral response and cell immunity, respectively. WILsON and NOSSAL ${ }^{1}$ and PERNIS ${ }^{2}$ have produced independent evidence for the ability of lymphocytes, in chronic lymphatic leukaemia (CLL), to bind anti-immunoglobulins, but to a much lesser extent than the normal B lymphocyte. This has been taken as evidence that the CLL lymphocyte is of the $B$ type, although atypical. with respect to its lower immunoglobulin content.
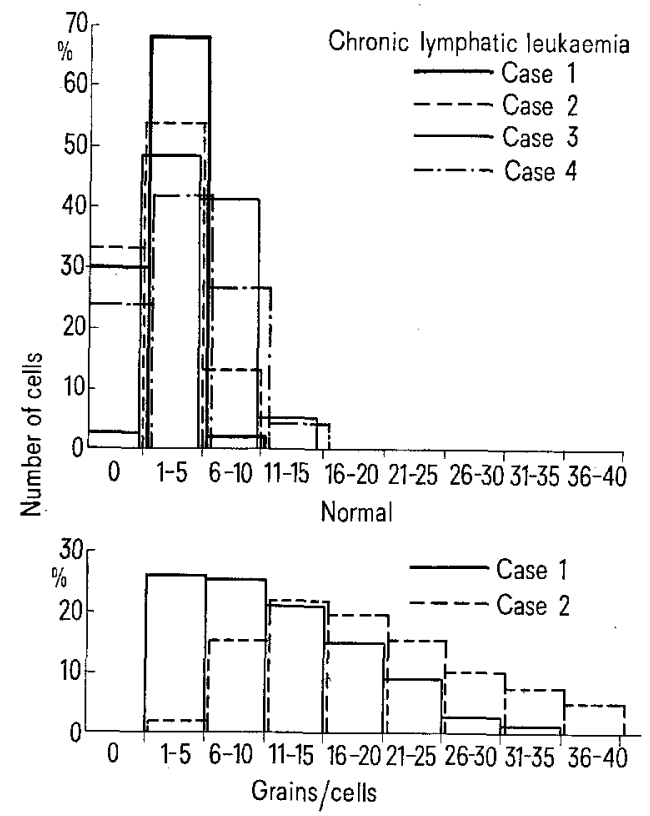

Grain count frequency histogram for normal blood (2 cases) and chronic lymphatic leukaemia lymphocytes (4 cases) following ${ }^{3} \mathrm{H}$ actinomycin labelling.
This below-normal immunoglobulin content may be considered as the result of disturbed genetic activity, i.e. of genetic repression. It was therefore decided to compare actinomycin binding, which can be taken as an expression of genetic activity (as shown by the increased binding observed in normal lymphocytes by DARZYNKIEwICZ et al. ${ }^{3}$ after phytohemagglutinin stimulation) in CLL and normal lymphocytes.

Actinomycin binding was therefore evaluated in 4 cases of CLL and in 2 normal subjects, by means of an in situ method, based on the measurement, after autoradiography, of ${ }^{3} \mathrm{H}$-actinomycin binding to the nuclei of smeared and fixed cells ${ }^{4}$.

The Figure shows that CLL lymphocytes were either incapable of binding actinomycin $\mathrm{D}$, or displayed binding values considerably below those found for the normal lymphocyte population by GavosTo and MASERA ${ }^{5}$.

These data, with respect to actinomycin binding as an expression of genetic activity, offer further evidence of the abnormal character of CLL lymphocytes. Depressed genetic activity might be directly responsible for their decreased immunoglobulin content ${ }^{1}$.

Zusammentassung. Lymphocyten von 4 Fällen chronischer lymphatischer Leukämie zeigten ein vermindertes Bindungsvermögen für ${ }^{3} \mathrm{H}$-Actinomycin.

P. Masera, A. Pileri, J. Brachet and N. Hulin ${ }^{6}$

Division of Haematology, Medical Clinic University of Torino, 14 Corso Polonia, I-10126 Torino (Italy); and Department of Molecular Biology, University of Bruxelles (Belgium), 18 May 1972.

1 J. D. WILSON and G. J. V. NosSAL, Lancet 1971, 788.

2 B. Pernis, L. Forni and L. Amante, Ann. N.Y. Acad. Sci. 190, 420 (1971).

3 Z. Darzynkiewicz, L. Bolund and N. R. Ringertz, Expl. Cell Res. 55, 120 (1969).

4 J. Brachet and N. Hulin, Nature 222, 481 (1969).

a F. Gavosto and P. Masera, to be published.

6 This work was supported by C.N.R., Rome.

\section{Hematopoietic Changes in NMRI Mice After the Intravenous and Subcutaneous Injection of Bordetella pertussis Vaccine}

The development of pronounced leukocytosis is one of the prominent features induced by killed pertussis organisms (PO) in man and experimental animals ${ }^{1,2}$. It is characterized by the increase in both the blood granulocyte $^{3-5}$ and lymphocyte ${ }^{6-8}$ counts. According to MoRse 7 the maximum is reached 4 days after the i.v. injection of $\mathrm{PO}$ and returns to normal by the 14th day. The same author reported that the route of injection is of crucial importance for the production of PO-mediated leukocytosis. The i.v. route was the most effective, whilst the s.c. route was ineffective. Although no plausible explanation could be given for this phenomenon?, there evidently exists a striking similarity to PO-mediated histamine sensitization which likewise was not produced by s.c. application 1,2,9-11. In our own experience, however, the s.c. injection of $\mathrm{PO}$ effects both increase in the blood leukocyte counts and marked splenomegaly.

Young adult female NMRI mice weighing 20-24 g were used. This strain of specifically pathogen-free mice was obtained from the Central Institute for Laboratory Animals in Hannover, Germany. In experiment A) 4 groups of mice were used. The animals of group I functioning as controls were treated by a single i.p. injection of $0.1 \mathrm{ml}$ of phosphate-buffered saline, $\mathrm{pH} 7.2$ (PBS). The other groups received $0.1 \mathrm{ml}$ of a Bordetella pertussis vaccine (phase 1 , not adsorbed but treated with merthiolate at a dilution of $1: 10,000$ for $30 \mathrm{~min}$ at $56^{\circ} \mathrm{C}$; OP-no. $678 \mathrm{a}$ of the Behring-Werke, Marburg, Germany) containing $3 \times 10^{10}$ PO per $\mathrm{ml}$. It was administered either by the i.p. (group II), i.v. (group III) or s.c. (group IV) route. At different intervals after treatment 5 to 6 mice out of each group were sacrificed, and the spleens were removed. Subsequently, the wet spleen weights were determined gravimetrically. The spleen index is defined as wet spleen weight/body weight $(\mathrm{mg} / \mathrm{g})$. The data presented in Table $I$ show that splenomegaly was most pronounced following the i.p. and i.v. injection of $P O$. The s.c. injection of PO also led to significant splenome- 